\title{
MEDIATION MODELS OF PREGNANCY DESIRES AND UNPLANNED PREGNANCY IN YOUNG, UNMARRIED WOMEN
}

\author{
WARREN B. MILLER*1 ${ }^{1}$, JENNIFER S. BARBER $\dagger$ AND HEATHER H. GATNY \\ *Transnational Family Research Institute, CA, USA, †Department of Sociology, \\ University of Michigan, Ann Arbor, MI, USA and $\ddagger$ Survey Research Center, University \\ of Michigan, Ann Arbor, MI, USA
}

\begin{abstract}
Summary. This paper examines the proposition that sexual and contraceptive behaviours mediate the relationship between the pregnancy desires of young, unmarried women and their having an unplanned pregnancy. The sample consisted of 854 18- to 19-year-old women living in Michigan, USA. First, the positive and negative pregnancy desires of these women were measured, as were the women's perceptions of the positive and negative desires of their sexual partners. Then the extent to which these four types of desires, as well as several types of interactions between them, prospectively predicted the occurrence of subsequent pregnancies were tested with logistic regression analyses, initially alone and then after the addition of several types of sexual and contraceptive mediator variables. The results demonstrated that four of the ten significant motivational predictors became non-significant following the introduction of the contraceptive mediator variables and that the predictive strength of the other six significant motivational predictors was substantially reduced by their introduction. A number of factors that may account for only a partial mediational effect in some models are discussed.
\end{abstract}

\section{Introduction}

Previous research has demonstrated the importance in married couples of both childbearing motivational traits and conscious desires as antecedents of childbearing intentions (Miller, 1994), with the intentions in turn being the antecedents of proceptive (pregnancy seeking) behaviours (Miller \& Pasta, 1995). Subsequent research has also demonstrated the importance of both childbearing motivational traits and pregnancy desires for contraceptive behaviour in married and unmarried couples (Miller \& Pasta, 2000, 2002). During the last decade, research has increasingly focused on how the positive and negative components of childbearing motivations and pregnancy desires interact to produce ambivalence and indifference, which in turn contribute to the risk of

${ }^{1}$ Corresponding author. Email: rennie@tfri.org 


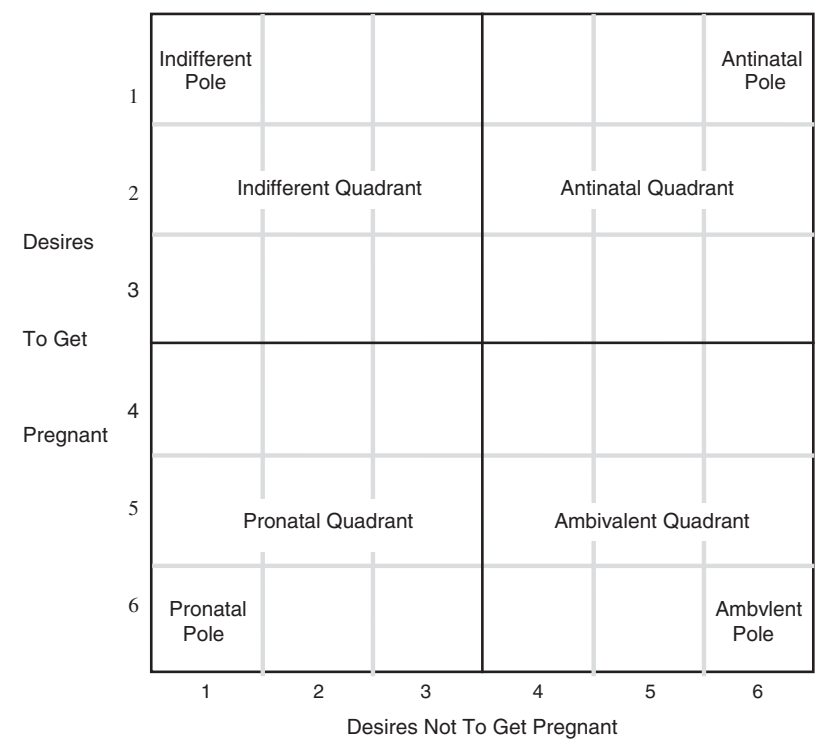

Fig. 1. A graphic representation of the interaction between two unipolar dimensions of pregnancy desires, one positive and the other negative, both varying from 1 to 6 . Source: Miller et al. (2013).

unplanned pregnancies among unmarried youth (Miller et al., 2013, 2014). During this same period, additional research has begun to focus on the extent to which women's perceptions of their partners' pregnancy desires contribute to the occurrence of unplanned pregnancies (Miller et al., 2016).

The current research reports a study of how the positive and negative components of pregnancy desires affect pregnancy rates in a large sample of 18- and 19-year-old unmarried women in the US and asks four questions of the data. First, do women's positive and negative pregnancy desires act through sexual and contraceptive behavioural mediators to affect their risk of pregnancy? Second, do interactions between the positive and negative components of their pregnancy desires act through these behavioural mediators? Third, do the women's perceptions of their partners' positive and negative pregnancy desires act through these mediators? And fourth, do the interactions between the positive and negative components of their own and their partners' perceived pregnancy desires act through these behavioural mediators? The primary goal of the current research is to compare the relative performance of the four types of models that are implicit in each of these questions.

The theoretical framework underlying this research makes a simplifying assumption that the positive and negative components of pregnancy desires are orthogonally related to each other, i.e. that they are largely uncorrelated. Figure 1 illustrates this interaction with two six-category pregnancy desires variables. The positive one, which is labelled along the left side of the figure, increases in strength from top to bottom, and the negative one, which is labelled across the bottom of the figure, increases in strength from left to right. Four quadrants are marked off with a bold horizontal and vertical line. Each quadrant is labelled according to the motivational implications of its specific 
positive and negative combinations, with each having its own motivational dynamic and each pair of diagonally opposed quadrants tending to manifest contrasting behaviours. Thus women located in the ambivalent quadrant would be expected to have a high-intensity conflict between their positive and negative pregnancy desires and exhibit an alternation across time of which of those two desires dominated their behaviour. In contrast, women located in the indifferent quadrant would be expected to have a low-intensity conflict between their positive and negative pregnancy desires without any clear dominance and exhibit behaviour that more often reflected situational factors, including the desires of their partners. With respect to the other two quadrants, women located in them would be expected to behave more consistently. Thus women located in the pronatal quadrant would be expected to have the goal of pregnancy reinforced by both high positive and low negative pregnancy desires and therefore be more likely to express their pregnancy desires through various proceptive behaviours. Similarly, women located in the antinatal quadrant would be expected to experience the same kind of internal and behavioural consistency as the pronatal women, although with a goal of pregnancy avoidance and the regular expression of contraceptive behaviour.

The smaller squares marked off with fainter lines in Fig. 1 indicate the specific strength combinations of positive and negative desires within the figure's overall framework. The four pole cells indicate the most extreme strength combinations possible. For example, the ambivalent pole cell would indicate women who had the highest possible score on both the desire for pregnancy and the desire to avoid pregnancy. The antinatal pole cell is unique because a very large proportion of the women included in the current study had the lowest possible score on the desire for pregnancy and the highest possible score on the desire to avoid pregnancy, an unsurprising finding in a group of unmarried late adolescent women. Previous research (Miller et al., 2013) established that the behaviour of those women was different enough from the rest of the women in the antinatal quadrant to justify separating them into two separate groups. Thus the antinatal quadrant is divided into a pole cell variable and a non-pole cells variable. These two variables, together with three variables based on each of the three non-antinatal quadrants shown in Fig. 1, are the basis for the five variables used in the first half of the analyses.

There is another type of interaction that is important for the second half of the analyses, one that is related to the potential contribution of the perceived partners' pregnancy desires to the mediation models. This type of interaction is between the women's five quadrant-based variables and the equivalent five variables derived from the women's perceptions of their partners' positive and negative desires. Figure 2 shows a five category by five category matrix representing this interaction. Each cell in this matrix represents a specific interaction, one that may or may not be unique in its effect on pregnancy risk. For example, women in the cell representing those who have ambivalent motivation and who perceive their partners as having pronatal motivation may be at a substantially different risk of pregnancy compared with women in the cell representing women who have ambivalent motivation but who perceive their partners as having antinatal polar motivation.

It is important to note that in order to study the differential risks related to each cell adequately a very large sample is necessary. The reason for this is that although a 


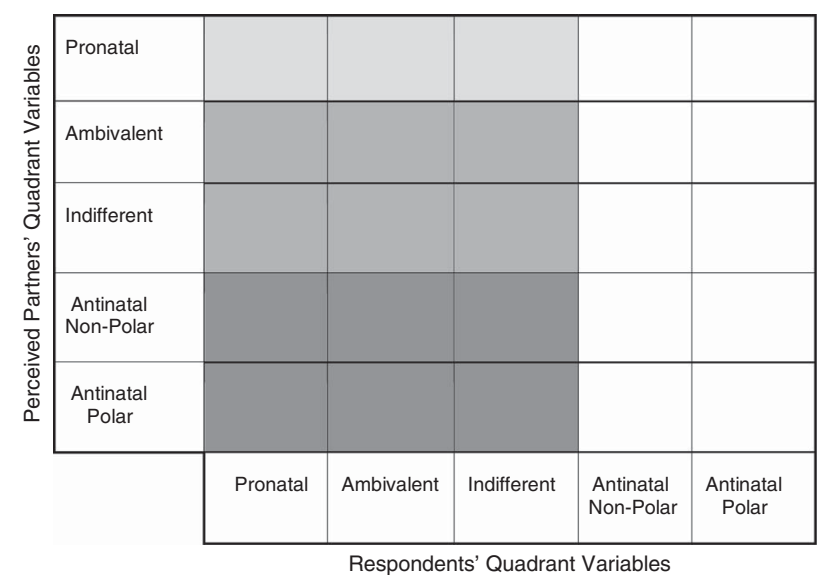

Fig. 2. A $5 \times 5$ matrix illustrating the interaction of the respondents' five quadrantbased desires variables with their perceived partners' five quadrant-based desires variables. Different intensities of background shading indicate which cells are constrained together to form each of the three perceived partners' predictor variables in the data analysis; see the Methods section. The respondents' antinatal polar and antinatal non-polar cells serve together as the reference in those analyses and have no background colour. Adapted from Miller et al. (2016).

modestly sized sample may well include enough women so that each of the 25 cells in the matrix have a sufficient number representing them to allow cross-cell comparisons, that sampling criterion does not meet all the requirements of the current study. The reason for this is because there must also be a number of women in each of the 25 cells who become pregnant in order for statistical estimations for each cell to be reliable. And because the proportion of women in any given cell who become pregnant even in a relatively large study may well turn out to be zero or just one, this additional requirement of pregnancies in each cell greatly expands the number of observations required. As a result, in the present study it was necessary to combine some cells in order to meet this requirement.

The shading of cells in Fig. 2 reflects one of the combinations arrived at in a previous study (Miller et al., 2016). In that study a number of different models of cell combinations were constructed, generally based on the question of whether the women's or their perceived partners' motivations were the better predictors of pregnancy. The one shown in Fig. 2 was one of the two most successful predictors in that study. It was chosen here because it was the more successful model when tested in the somewhat larger sample used in the current study. Specifically, the model shown in Fig. 2 is based on three perceived partner variables that respectively reflect pronatal motivation, combined ambivalent/indifferent motivation and combined non-polar and polar antinatal motivation. Each of these three perceived partner's motivational variables is shown with different background shading. There is no background shading for the women's own combined non-polar and polar antinatal motivation, which serves as the reference category for the three perceived partner variables in the data analysis. 


\section{Methods}

\section{Study design and sample}

Data previously collected during the Relationship Dynamics and Social Life (RDSL) study (Barber et al., 2011) were used in the current study. These data were based on a random, population-based sample of 1003 women aged 18-19 who resided in a single county in Michigan, USA. The women were interviewed for 60 minutes, face-to-face, between March 2008 and July 2009, with the focus on family background, sexual relationships, contraceptive use, pregnancy history and current pregnancy desires. All interviewed women were then invited, and offered incentives, to participate in a weekly journal-based, mixedmode (internet and telephone) survey that would track pregnancy status for 2.5 years. Cooperation was high, with an $84 \%$ response rate for the baseline interview, $99 \%$ agreeing to participate in the survey and $75 \%$ participating for at least 18 months.

This research was approved by the University of Michigan's Health Sciences and Behavioural Sciences IRB (IRB-HSBS). The IRB study ID for the data collection was HUM00014150. The IRB study ID for secondary analysis was HUM00084379. All research participants provided written informed consent before beginning the baseline interview. No women younger than 18 years of age was included in this study; therefore, individuals provided their own written consent and their parents were not consulted. As part of the informed consent process, participants were informed that they could leave the study at any time, for any reason.

Weekly data from 992 women who had completed 58,594 journals were used. A woman $(w)$ or her selected journals $(j)$ were excluded from the study as follows: if the woman had no intimate partner at present $(j)$ or, for some other reason, was not at risk of pregnancy $(w, j)$; if she got married during the study or was already married $(w, j)$; if she dropped out after only one week in the study $(w)$; if a pregnancy could not be linked to a specific partner $(j)$; or if there were missing data about her own desires or the perceived desires of her partner $(j)$. Excluded perforce was any week or series of weeks that a journal was not completed by the woman. After these exclusions, the group remaining was comprised of 854 women who had completed 31,122 journals.

\section{Measures}

Desires-related predictor variables. The two core time-varying variables of positive and negative pregnancy desires were measured with the following two questions: 1) First, how much do you want to get pregnant during the next month? Please give me a number between 0 and 5, where 0 means you don't at all want to get pregnant and 5 means you really want to get pregnant. 2) And next, how much do you want to avoid getting pregnant during the next month? Please give me a number between 0 and 5 , where 0 means you don't at all want to avoid getting pregnant and 5 means you really want to avoid getting pregnant.

When these two questions were asked during the initial interview there was an introduction explaining that most people their age have both positive and negative feelings about getting pregnant and having a child. This explanation was not reiterated during the follow-up, journal-based survey. 
Table 1. Descriptive statistics of respondents' and perceived partners' pregnancy desires, $N=31,122$ journal observations from 854 young women

\begin{tabular}{|c|c|c|c|c|c|c|}
\hline & \multicolumn{4}{|l|}{$\begin{array}{c}\text { Low } \\
\text { desires }\end{array}$} & \multicolumn{2}{|r|}{$\begin{array}{l}\text { High } \\
\text { desires }\end{array}$} \\
\hline & 1 & 2 & 3 & 4 & 5 & 6 \\
\hline \multicolumn{7}{|l|}{ Frequency distributions of core variables } \\
\hline \multicolumn{7}{|l|}{ Respondents' desires } \\
\hline Desires to become pregnant (positive desires) & 28,528 & 474 & 372 & 914 & 332 & 502 \\
\hline Desires to avoid pregnancy (negative desires) & 606 & 239 & 413 & 868 & 770 & 28,226 \\
\hline \multicolumn{7}{|l|}{ Perceived partners' desires } \\
\hline Desires to become pregnant (positive desires) & 27,343 & 686 & 572 & 1081 & 470 & 970 \\
\hline Desires to avoid pregnancy (negative desires) & 1022 & 300 & 581 & 1229 & 917 & 27,073 \\
\hline \multicolumn{7}{|c|}{ Percentages of journal observations for quadrant-based dummy variables } \\
\hline \multicolumn{7}{|c|}{ Respondents' desires } \\
\hline Pronatal dummy & $3.07 \%$ & & & & & \\
\hline Ambivalent dummy & $2.55 \%$ & & & & & \\
\hline Indifferent dummy & $0.98 \%$ & & & & & \\
\hline Antinatal non-pole-cells dummy & $3.32 \%$ & & & & & \\
\hline Antinatal pole-cell dummy & $90.09 \%$ & & & & & \\
\hline \multicolumn{7}{|l|}{ Perceived partners' desires } \\
\hline Pronatal dummy & $4.92 \%$ & & & & & \\
\hline Ambivalent dummy & $3.18 \%$ & & & & & \\
\hline Indifferent dummy & $1.20 \%$ & & & & & \\
\hline Antinatal non-pole-cells dummy & $4.44 \%$ & & & & & \\
\hline Antinatal pole-cell dummy & $86.26 \%$ & & & & & \\
\hline
\end{tabular}

Source: Relationship Dynamics and Social Life study.

The two other core variables of perceived partner positive and negative pregnancy desires were measured with the following two questions: 1) How much do you think wants you to get pregnant during the next month? Please give me a number between 0 and 5, where 0 means you think he doesn't at all want you to get pregnant and 5 means you think he really wants you to get pregnant. 2) How much do you think ........... wants you to avoid getting pregnant during the next month? Please give me a number between 0 and 5, where 0 means you think he doesn't at all want you to avoid getting pregnant and 5 means you think he really wants you to avoid getting pregnant. Frequency distributions of all four of these core variables are presented in the top half of Table 1.

Using these four core variables, five dichotomous, quadrant-based dummy variables corresponding to the categories in Miller et al. (2013) and based on Fig. 1 were created for each woman. Three of those dummy variables were based on those cases where the woman's positive and negative pregnancy desires both fell within either the pronatal, ambivalent or indifferent quadrants; a fourth dummy variable was based on all cases that fell within the antinatal quadrant, excepting the pole cell; and a fifth dummy variable was based on all cases that fell within the single pole cell of the antinatal quadrant. These five quadrant-based dummy variables are referred to as the 
women's pronatal, ambivalent, indifferent, antinatal non-polar and antinatal polar pregnancy desires.

Next, five equivalent dichotomous, quadrant-based dummy variables were created, based on the women's perception of their partners' positive and negative pregnancy desires. These five quadrant-based dummy variables are referred to as the perceived partners' pronatal, ambivalent, indifferent, antinatal non-polar and antinatal polar pregnancy desires. The percentages of total journal observations for all ten of these quadrant-based variables are presented in the bottom half of Table 1.

Finally, as presented in Fig. 2, each of the women's five quadrant-based dummy variables were interacted with each of the perceived partner's five quadrant-based dummy variables in a 25-cell matrix, where each cell represented all women with a unique combination of their own desires and perception of their partners' desires. The three perceived partner predictor variables shown in that figure were then constructed by constraining the indicated cells together into what are referred to as the perceived partners' constrained pronatal desires $(2.67 \%)$, constrained ambivalent/indifferent desires $(2.23 \%)$ and constrained antinatal desires (1.70\%). Regardless of their partners' motivation, all of the women's antinatal non-polar and polar cells were constrained together $(95.4 \%)$ into what are referred to as the women's constrained antinatal desires, which served as the reference category in the analyses. (The figures in parentheses represent the percentages of journal observations for each of these four variables.)

Outcome variable. In their weekly journals, the women were asked if they thought they might be pregnant. If the answer was 'yes', they were asked 'Has a pregnancy test indicated that you are pregnant?' If that answer was 'yes', they were coded 1 on a pregnancy dummy variable. Information about the type of pregnancy test taken by the respondents was not collected. However, pregnancy tests administered in clinical settings are extremely accurate and home pregnancy tests are reasonably accurate as well, with some able to predict $97 \%$ of pregnancies on the day of missed menses (Cole, 2011).

The time when the pregnancy was thought to have actually begun was identified according to a series of rules that linked every pregnancy with a reported sexual partner. Although it is impossible to measure the exact date of conception for any naturally occurring pregnancy, by collecting information about both relationships and pregnancy on a weekly basis, it was possible to estimate the journal nearest to conception. To do this information about the father of the pregnancy provided by the respondent was used to pinpoint the journal when conception most likely occurred. For most cases, the father identified at the new pregnancy week was the same as the partner reported 3 weeks prior to the new pregnancy week. In those cases, conception was coded 2 weeks prior to the new pregnancy week. For other cases, conception was coded up to 11 weeks prior to the new pregnancy, depending on the information provided about the father. All of this work was done on a case-by-case basis in order to ensure the most accurate estimates possible. In the analytic sample, 158 of the 854 women reported a pregnancy: 130 reported one, 26 reported two and 2 reported three, for a total of 188 pregnancies.

Mediator variables. Four mediator variables were constructed from journal data. One, a dichotomous variable, was based on whether or not the women reported sexual intercourse during the previous week. The second, a categorical variable, was based on 
Table 2. Percentages of journal observations for categories of variables used as mediators in the data analyses, $N=31,122$ journal observations from 854 young women

\begin{tabular}{lr}
\hline Characteristic & $\%$ \\
\hline Sexual intercourse the prior week & \\
No & 46.0 \\
Yes (Ref.) & 54.0 \\
Sex/contraceptive consistency the prior week & \\
No sex, yes contraception & 17.9 \\
No sex, no contraception & 28.1 \\
Yes sex, consistent contraception & 37.9 \\
Yes sex, inconsistent contraception & 9.7 \\
Yes sex, no contraception (Ref.) & 6.4 \\
Sex/contraceptive method the prior week & \\
No sex, other hormonal & 2.0 \\
No sex, pill & 12.3 \\
No sex, coital & 0.0 \\
No sex, used nothing & 31.7 \\
Yes sex, other hormonal & 5.8 \\
Yes sex, pill & 21.4 \\
Yes sex, coital & 20.1 \\
Yes sex, used nothing (Ref.) & 6.7 \\
Perceived subfecundity & \\
No (Ref.) & 82.3 \\
Yes, self-observation or medical doctor & 13.1 \\
Yes, both self and medical doctor & 4.6 \\
\hline
\end{tabular}

Ref.: reference category.

${ }^{a}$ Includes the morning-after pill.

Source: Relationship Dynamics and Social Life study.

an interaction between the sexual behaviour variable and whether the women reported using any form of contraception during the previous week, and if so, how consistent their use was. A third variable, also categorical, was based on an interaction between the sexual behaviour variable and the types of contraception the women reported using during the previous week. The fourth variable, an ordinal measure of perceived subfecundity, was based on two questions asked of all women during the initial interview: had they ever thought they might not be able to get pregnant and had they ever been told by a doctor that they might not be able to get pregnant? Percentage distributions of all four of these variables are presented in Table 2.

Control variables. The women were asked about a large number of their background characteristics at the baseline interview. From these data, eleven control variables were constructed for the data analysis as follows: age (continuous variable); high school grade point average (continuous variable, with those who did not know their grade point average assigned a score, 2.54 , which was one standard deviation below the overall mean score); religious importance (a dummy variable, with the two more important categories 
coded 1); race (African-American as a dummy variable); childhood disadvantage (an ordinal variable based on the sum of the following four dummy variables: did not live with two parents, at least one of which was biological, during childhood, with the last two categories coded 1; age of biological mother at first birth, with the $<20$ coded 1; mother's education, with < high school coded 1; and childhood public assistance, with 'yes' coded 1); current public assistance (a dummy variable, with 'yes' coded 1); age at first sex (a dummy variable, with $\leq 16$ coded 1 ); number of sexual partners (a dummy variable, with $>1$ coded 1); currently cohabiting (a dummy variable, with 'yes' coded 1); ever had sex without birth control (a dummy variable, with 'yes' coded 1); and number of pregnancies (a dummy variable, with $>0$ coded 1). The frequency distributions of the respondents' background characteristics are shown in Table 3.

Not shown in Table 3 are three additional control variables. Months in study $($ mean $=12.0, \mathrm{SD}=8.63)$ and months in study squared $($ mean $=218.1, \mathrm{SD}=246.7)$ measured the length of the interval(s) a woman had been at risk of pregnancy, thereby controlling for actual risk exposure. Number of journals (mean $=89.3, \mathrm{SD}=33.4$ ) indicated the total number of observations a woman had contributed to the data, thereby controlling for the effect of repeated measurement and the woman's level of participation in the study.

\section{Data analysis}

Analyses were conducted using Stata/MP Version 14.1 (www.stata.com). Hazard models were estimated using random effects, multi-level logistic regression to analyse the effects of pregnancy desires on pregnancies. The dependent variable was a time-varying $1 / 0$ binary measure of whether a pregnancy occurred in a given week. Multi-level models were used because there were multiple observations for each woman, with some covariates varying at the individual observation level and some varying only at the woman level. Finally, random-effects models were used in order to allow the slopes and intercepts estimated by the model to vary across individual women, thereby allowing the women-specific effects to be modelled. Because the data were precise to the week, discrete-time methods were used to estimate these models. Person-weeks of exposure were the units of analysis. All pregnancies reported by each woman were examined and a time-varying control variable indicating the number of prior pregnancies was also included. Women were considered to be at risk of pregnancy during all weeks that they reported they were in an intimate relationship and not currently pregnant. Consequently, weeks in which a woman was not in a relationship or was currently pregnant were excluded from the analyses.

The time-varying measures of pregnancy desires and perceived partner pregnancy desires that were linked to a subsequent pregnancy in the data analytic models were measured at the point of data collection that was one week prior to when the pregnancy was thought to have actually begun. (If information about pregnancy desires was ever missing for the week prior to conception, information from 2 weeks prior to conception was used.) This strategy was adopted so that the woman's desires would be measured prior to the sexual intercourse that had resulted in her pregnancy, thereby guarding against reciprocal causation, i.e. guarding against the woman's discovery that she was pregnant affecting how she reported her pregnancy desires. 
Table 3. Frequency distributions of the respondents' characteristics used as control variables in the data analyses, $N=31,122$ journal observations from 854 young women

Age

High school GPA ${ }^{\mathrm{a}}$

$0-1.99$

2.0-2.99

3.0-3.99

$\geq 4.0$

Don't know $=2.54(1 \mathrm{SD}<$ mean GPA $)$

Importance of religion

Not important

Somewhat important

Very important

More important than anything

Race

African-American

White

Other

Refused, don't know, missing

Lived mostly with parents during childhood

Yes, two biological or adoptive parents

Yes, one biological and one step-parent

Yes, one biological parent only

No, other

Age of biological mother at first birth

Refused, don't know

Mother's education

$<$ High school

High school graduate $\quad 282$

$\begin{array}{ll}\text { Some college } & 287\end{array}$

$\begin{array}{lr}\geq B A & 180\end{array}$

Refused, don't know, missing 32

Received childhood public assistance

Yes

No

Refused, don't know

Currently receiving public assistance 
Table 3. Continued

\begin{tabular}{lr}
\hline Characteristic & $n$ \\
\hline Age at first sex & \\
$<15$ & 144 \\
$15-16$ & 311 \\
$17-19$ & 224 \\
Never & 172 \\
Refused, don't know & 3 \\
Total number of lifetime sexual partners & \\
None & 174 \\
1 & 151 \\
$2-3$ & 225 \\
$4-6$ & 175 \\
$>6$ & 114 \\
Refused, don't know & 15 \\
Currently cohabiting & \\
No & 510 \\
Yes & 156 \\
No current partner & 188 \\
Ever had sexual intercourse without birth control & \\
Yes & 417 \\
No & 255 \\
Missing & 182 \\
Number of pregnancies & \\
0 & 638 \\
1 & 143 \\
2 & 43 \\
$>2$ & 29 \\
Don't know & 1 \\
\hline
\end{tabular}

${ }^{\mathrm{a}}$ GPA: Grade Point Average.

Source: Relationship Dynamics and Social Life study.

Four models were constructed and estimated. These models were designed to determine the degree to which the desires variables directly predicted the occurrence of pregnancies and then to determine the extent to which introduction of the sexual variable alone and the sexual and contraceptive variables in interaction, acted as mediators and thereby reduced that direct prediction. The first (base) model included the pregnancy desires predictor variables and the control variables and included no mediator variables. The second model added the sexual behaviour mediator variable to the base model. The third model added a variable based on the interaction between sexual behaviour and contraceptive consistency to the base model. Finally, the fourth model added a variable based on the interaction between sexual behaviour and contraceptive method to the base model. During the preliminary estimation of these four models, the perceived subfecundity variable (described in connection with Table 2 as an additional mediator variable) was also included. However, there were no significant effects of perceived fecundity in any of the models and no discernable effects on the other 
mediator variables in the three mediation models. The perceived fecundity variable was therefore dropped from all models and further consideration.

The four models just described were next tested with each of four different groups of pregnancy desires predictor variables. These included: 1) the women's positive and negative pregnancy desires; 2) the women's quadrant-based pronatal, ambivalent, indifferent and antinatal non-polar pregnancy desires; 3) the perceived partners' positive and negative pregnancy desires; and 4) the perceived partners' constrained pronatal, ambivalent/indifferent and antinatal desires. These four groups of predictors were selected on the basis of findings from previous research (Miller et al., 2013, 2016).

\section{Results}

Table 4 shows the results of testing the four models with the core positive and negative pregnancy desires as the predictor variables. (The control variable results are not shown in this and the following three tables but will be discussed following the tabular presentations.) In the base model without mediators, the women's core negative desires are highly significant in the prediction of no pregnancy occurring and their core positive desires are only slightly significant in the prediction of a pregnancy occurring. Adding the sexual behaviour variable to the base model makes virtually no difference and the sexual behaviour variable is itself non-significant.

Adding the sexual behaviour/contraceptive consistency variables to the base model makes positive desires non-significant and appreciably reduces the significance of negative desires. It also considerably reduces the model's negative log-likelihood, indicating a better performing model. Women having sex with consistent contraception have a highly significant reduction in pregnancy risk relative to the reference category of women having sex with no contraception, while those having sex with inconsistent contraception have only a modestly significant reduction in pregnancy risk. As would be expected, both categories of women who reported having no sex also had a reduced risk of pregnancy. However, in these two categories there is a smaller risk reduction among women who reported not using contraception. This finding most likely indicates that some women in both of the two no-sex categories were correctly classified with respect to contraceptive consistency but incorrectly classified with respect to which week they were having sex. Such a measurement error would mean that some women included in both of the no-sex categories in fact did have sex, which in turn would reduce the negative coefficients of both categories, especially for the non-users.

Adding the sexual behaviour/type of contraception variable to the base model has similar effects to adding the sexual behaviour/contraceptive consistency variable in making positive desires non-significant and reducing the significance of negative desires. It also reduces the model's negative log-likelihood to an even greater extent. Women having sex with each of the three categories of contraceptive methods have a highly significant reduction of pregnancy risk relative to the reference category of sex using no method, with the relative strength of the coefficients being roughly proportional to the generally recognized use effectiveness of the three categories. As again would be expected, the three categories of women reporting no sex have a reduced risk of pregnancy and here too the pattern across the categories suggests the effects of measurement error. Thus comparing the two method type categories that are 
Table 4. Models testing the sexual and contraceptive behavioural mediation between the women's positive and negative pregnancy desires and their risk of pregnancy, $N=854$ women, 31,122 journals

\begin{tabular}{|c|c|c|c|c|}
\hline \multirow[b]{2}{*}{ Core desires measures } & \multicolumn{4}{|c|}{ Coefficients } \\
\hline & & & & \\
\hline Desires to become pregnant & $\begin{array}{c}0.17 * \\
(0.08)\end{array}$ & $\begin{array}{c}0.17^{*} \\
(0.08)\end{array}$ & $\begin{array}{c}0.06 \\
(0.09)\end{array}$ & $\begin{array}{c}0.07 \\
(0.09)\end{array}$ \\
\hline Desires to avoid pregnancy & $\begin{array}{c}-0.27^{* * *} \\
(0.08)\end{array}$ & $\begin{array}{c}-0.27 * * * \\
(0.08)\end{array}$ & $\begin{array}{c}-0.21 * * \\
(0.08)\end{array}$ & $\begin{array}{c}-0.20^{*} \\
(0.08)\end{array}$ \\
\hline Mediator variables & & & & \\
\hline Sex prior week & & $\begin{array}{c}0.04 \\
(0.17)\end{array}$ & & \\
\hline No sex, contraception & & & $\begin{array}{c}-1.94 * * * \\
(0.34)\end{array}$ & \\
\hline No sex, no contraception & & & $\begin{array}{c}-1.01^{* *} \\
(0.24)\end{array}$ & \\
\hline Sex, consistent contraception & & & $\begin{array}{c}-1.98 * * * \\
(0.25)\end{array}$ & \\
\hline Sex, inconsistent contraception & & & $\begin{array}{c}-1.28^{* * *} \\
(0.26)\end{array}$ & \\
\hline No sex, other hormonal & & & & $\begin{array}{c}-3.03^{* *} \\
(1.04)\end{array}$ \\
\hline No sex, pill & & & & $\begin{array}{l}-2.50^{* * * *} \\
(0.55)\end{array}$ \\
\hline No sex, nothing & & & & $\begin{array}{l}-1.00^{* * *} \\
(0.23)\end{array}$ \\
\hline Sex, other hormonal & & & & $\begin{array}{c}-2.74 * * * \\
(0.55)\end{array}$ \\
\hline Sex, pill & & & & $\begin{array}{l}-2.00^{* * * *} \\
(0.33)\end{array}$ \\
\hline Sex, coital & & & & $\begin{array}{c}-1.42^{* * * *} \\
(0.24)\end{array}$ \\
\hline Log-likelihood & -1010.80 & -1010.77 & -975.33 & -970.29 \\
\hline Pseudo $R^{2}$ & 0.10 & 0.10 & 0.13 & 0.14 \\
\hline
\end{tabular}

${ }^{*} p<0.05 ;{ }^{* *} p<0.01 ;{ }^{* * *} p<0.001$.

comparable for women reporting either sex or no sex - namely those using other hormonal methods and those using the pill - the no-sex categories may be seen to indicate a greater risk reduction in both cases. Further, those women having sex and using coital methods have the least protection among those using a method and those not having sex but using nothing have the least protection of all six categories. These patterns are consistent with a protective effect of no sex and an interpretation of measurement error in the case of the no-sex category.

Table 5 shows the results of testing the same four models with the four quadrantbased dummy variables derived from the women's positive and negative desires as the 
Table 5. Models testing the sexual and contraceptive behavioural mediation between four quadrant-based dummy variables representing the women's positive and negative pregnancy desires and their risk of pregnancy, $N=854$ women, 31,122 journals

\begin{tabular}{|c|c|c|c|c|}
\hline \multirow{2}{*}{ Core desires measures } & \multicolumn{4}{|c|}{ Coefficients } \\
\hline & & & & \\
\hline \multirow[t]{2}{*}{ Pronatal dummy } & $1.81 * * *$ & $1.80 * * *$ & $1.19^{* * *}$ & $1.20^{* * *}$ \\
\hline & $(0.31)$ & $(0.31)$ & $(0.33)$ & $(0.33)$ \\
\hline \multirow[t]{2}{*}{ Ambivalent dummy } & $1.57 * * *$ & $1.57 * * *$ & $1.09^{* * *}$ & $1.10^{* * *}$ \\
\hline & $(0.35)$ & $(0.35)$ & $(0.36)$ & $(0.36)$ \\
\hline \multirow[t]{2}{*}{ Indifferent dummy } & $1.55^{* * *}$ & $1.55^{* * *}$ & $1.25^{* * *}$ & $1.21 * * *$ \\
\hline & $(0.27)$ & $(0.27)$ & $(0.29)$ & $(0.29)$ \\
\hline \multirow[t]{2}{*}{ Antinatal non-polar dummy } & $0.90 * *$ & $0.89 * *$ & 0.62 & 0.58 \\
\hline & $(0.32)$ & $(0.32)$ & $(0.33)$ & $(.33)$ \\
\hline \multicolumn{5}{|l|}{ Mediator variables } \\
\hline Sex prior week & & $\begin{array}{c}0.05 \\
(0.17)\end{array}$ & & \\
\hline No sex, contraception & & & $\begin{array}{c}-1.89 * * * \\
(0.34)\end{array}$ & \\
\hline No sex, no contraception & & & $\begin{array}{c}-0.97 * * * \\
(0.24)\end{array}$ & \\
\hline Sex, consistent contraception & & & $\begin{array}{c}-1.93^{* * *} \\
(0.26)\end{array}$ & \\
\hline Sex, inconsistent contraception & & & $\begin{array}{c}-1.25^{* * * *} \\
(0.26)\end{array}$ & \\
\hline No sex, other hormonal & & & & $\begin{array}{c}-2.99 * * \\
(1.04)\end{array}$ \\
\hline No sex, pill & & & & $\begin{array}{c}-2.45^{* * *} \\
(0.56)\end{array}$ \\
\hline No sex, nothing & & & & $\begin{array}{c}-0.97 * * * \\
(0.23)\end{array}$ \\
\hline Sex, other hormonal & & & & $\begin{array}{c}-2.69^{* * *} \\
(0.56)\end{array}$ \\
\hline Sex, pill & & & & $\begin{array}{c}-1.95^{* * *} \\
(0.33)\end{array}$ \\
\hline Sex, coital & & & & $\begin{array}{c}-1.38^{* * * *} \\
(0.24)\end{array}$ \\
\hline Log-likelihood & -1005.91 & -1005.87 & -972.10 & -967.06 \\
\hline Pseudo $R^{2}$ & 0.11 & 0.11 & 0.14 & 0.14 \\
\hline
\end{tabular}

${ }^{*} p<0.05 ; * * p<0.01 ; * * * p<0.001$.

predictor variables and the women's antinatal polar dummy as the reference. In the base model, the first three quadrant-based desires predictors are highly significant in the prediction of pregnancy risk and remain so across the three mediation models, although coefficient strength decreases appreciably in the second and third mediation models. The antinatal non-polar dummy, consistent with previous findings (Miller et al., 2013), is somewhat less significant than the first three dummies in the base model and becomes 
Table 6. Models testing the sexual and contraceptive behavioural mediation between the women's perceived partners' positive and negative pregnancy desires and their risk of pregnancy, $N=854$ women, 31,122 journals

\begin{tabular}{|c|c|c|c|c|}
\hline \multirow{2}{*}{ Core desires measures } & \multicolumn{4}{|c|}{ Coefficients } \\
\hline & & & & \\
\hline Perceived partners' desires to become pregnant & $\begin{array}{l}0.23^{* *} \\
(0.08)\end{array}$ & $\begin{array}{l}0.23^{* *} \\
(0.08)\end{array}$ & $\begin{array}{c}0.15 \\
(0.08)\end{array}$ & $\begin{array}{c}0.15 \\
(0.08)\end{array}$ \\
\hline Perceived partners' desires to avoid pregnancy & $\begin{array}{c}-0.14 \\
(0.08)\end{array}$ & $\begin{array}{c}-0.14 \\
(0.08)\end{array}$ & $\begin{array}{c}-0.10 \\
(0.09)\end{array}$ & $\begin{array}{c}-0.11 \\
(0.08)\end{array}$ \\
\hline \multicolumn{5}{|l|}{ Mediator variables } \\
\hline Sex prior week & & $\begin{array}{c}0.05 \\
(0.17)\end{array}$ & & \\
\hline No sex, contraception & & & $\begin{array}{c}-1.90^{* * *} \\
(0.33)\end{array}$ & \\
\hline No sex, no contraception & & & $\begin{array}{c}-0.96^{* * *} \\
(0.24)\end{array}$ & \\
\hline Sex, consistent contraception & & & $\begin{array}{l}-1.92^{* * *} \\
(0.26)\end{array}$ & \\
\hline Sex, inconsistent contraception & & & $\begin{array}{c}-1.25^{* * *} \\
(0.26)\end{array}$ & \\
\hline No sex, other hormonal & & & & $\begin{array}{c}-3.03^{* *} \\
(1.04)\end{array}$ \\
\hline No sex, pill & & & & $\begin{array}{l}-2.44^{* * *} \\
(0.55)\end{array}$ \\
\hline No sex, nothing & & & & $\begin{array}{l}-0.95^{* * *} \\
(0.23)\end{array}$ \\
\hline Sex, other hormonal & & & & $\begin{array}{l}-2.70^{* * *} \\
(0.55)\end{array}$ \\
\hline Sex, pill & & & & $\begin{array}{c}-1.92^{* * *} \\
(0.33)\end{array}$ \\
\hline Sex, coital & & & & $\begin{array}{c}-1.37^{* * *} \\
(0.24)\end{array}$ \\
\hline Log-likelihood & -1008.61 & -1008.56 & -974.50 & -968.78 \\
\hline Pseudo $R^{2}$ & 0.10 & 0.10 & 0.13 & 0.14 \\
\hline
\end{tabular}

non-significant in the second and third mediation models. The overall pattern of the mediation models here is similar to that in the previous table, with the third one based on the sexual behaviour/type of contraception variable again having the lowest negative log-likelihood and, therefore, being the best performing model in this table.

Table 6 shows the results of testing the same four models while using the core perceived partners' positive and negative pregnancy desires as the predictor variables. In the base model, only the perceived partners' core positive desires are significant and this predictor also becomes non-significant with the addition of mediators. This is the opposite pattern from that shown in Table 4, where it is the women's core negative pregnancy desires that are non-significant, although in this table both core pregnancy 
desires variables are reduced to non-significance with the addition of the two sexual behaviour/contraceptive behaviour mediators. Again, the overall pattern within the mediation models is similar to that in the previous tables and the final mediation model also has the lowest negative log-likelihood for this group of models.

Table 7 shows the results of testing the same four models with the three perceived partners' constrained desires variables used as predictors and the women's constrained antinatal desires as the reference. As with the base model of Table 5, which showed the results for the women's quadrant-based dummy variables, the results in the comparable base model are also highly significant. However, in this case the three predictors have a differential strength of coefficients. In addition, they lose that strength differentially following the addition of the mediator variables, with the perceived partners' constrained ambivalent/indifferent dummy becoming non-significant in the last two mediation models and the perceived partners' constrained pronatal dummy best retaining its significance. The negative log-likelihood of the final mediation model is the lowest in all four tables, indicating that the combination of variables based on sexual behaviour and type of contraceptive method is the best performing mediator of the four that have been tested and that the group of perceived partners' constrained desires variables is the best performing of the four groups that have been tested.

The performance of the control variables was consistent across all models. The following are the observed control variable coefficients for the base model and the best performing mediation model. Of the fourteen control variables, the following three had significant positive coefficients: age at first sex $\leq 16$ years $(0.52 * / 0.61 *)$, one or more prior pregnancies $\left(0.57 * / 0.55^{*}\right)$, months in study $\left(0.12^{* * *} / 0.12^{* * *}\right)$; and the following three variables had significant negative coefficients: high school grade point average $\left(-0.38 * * /-0.33^{*}\right)$, months in study squared $\left(-0.00^{* * *} /-0.00^{* * *}\right)$ and number of journals $\left(-0.02^{* * *} /-0.02^{* * *}\right)$, where two-tailed $p$-values are: ${ }^{*} p<0.05, * * p<0.01$ and ${ }^{* * *} p<0.001$.

In order to quantify the extent to which the introduction of mediator variables reduced the prediction of pregnancy risk by the preconception desires variables and their derivatives, selected coefficients of the predictor variables shown in Tables 4 to 7 were transformed into $t$-ratios by dividing each one by its standard error. These transformations allowed two sets of comparisons. First, the $t$-ratios of the base (first) models in Tables 4-7 before the addition of the control variables were compared with those after the addition of the control variables, and the percentage differences in the $t$-ratios that resulted from these additions were calculated. Second, the $t$-ratios of the base models in Tables 4-7 were compared with those of the last (fourth) models in Tables 4-7 (i.e. the ones that consistently had the best performing mediators) and the percentage differences in their $t$-ratios were calculated, in both cases after the addition of the control variables.

The mean $t$-ratio score decrease that resulted from adding the control variables to the four base models that contained eleven pregnancy desires related predictors was $14.5 \%$, with a relatively narrow range of $5.6 \%$ to $26.4 \%$. As a result of this addition, the only $t$-ratio score that became non-significant was for the predictor based on the perceived partners' desires to avoid pregnancy, having decreased by $15.2 \%$. The corresponding mean $t$-ratio score decrease that resulted from adding the best performing mediator 
Table 7. Models testing the sexual and contraceptive behavioural mediation between three interaction dummy variables representing the women's perceived partners' constrained positive and negative pregnancy desires and their risk of pregnancy, $N=854$ women, 31,122 journals

\begin{tabular}{|c|c|c|c|c|}
\hline \multirow[b]{2}{*}{ Core desires measures } & \multicolumn{4}{|c|}{ Coefficients } \\
\hline & & & & \\
\hline $\begin{array}{l}\text { Perceived partners' constrained pronatal } \\
\text { dummy }\end{array}$ & $\begin{array}{l}2.20^{* * *} \\
(0.25)\end{array}$ & $\begin{array}{l}2.19^{* * * *} \\
(0.26)\end{array}$ & $\begin{array}{l}1.52^{* * *} \\
(0.28)\end{array}$ & $\begin{array}{l}1.57 * * * \\
(0.28)\end{array}$ \\
\hline $\begin{array}{l}\text { Perceived partners' constrained amb/indiff } \\
\text { dummy }\end{array}$ & $\begin{array}{l}0.92 * * \\
(0.35)\end{array}$ & $\begin{array}{l}0.92^{* *} \\
(0.35)\end{array}$ & $\begin{array}{c}0.42 \\
(0.37)\end{array}$ & $\begin{array}{l}0.39 \\
(0.37)\end{array}$ \\
\hline $\begin{array}{l}\text { Perceived partners' constrained antinatal } \\
\text { dummy }\end{array}$ & $\begin{array}{l}1.23^{* * *} \\
(0.35)\end{array}$ & $\begin{array}{l}1.23^{* * *} \\
(0.35)\end{array}$ & $\begin{array}{l}1.04^{* *} \\
(0.36)\end{array}$ & $\begin{array}{l}1.03^{* *} \\
(0.36)\end{array}$ \\
\hline \multicolumn{5}{|l|}{ Mediator variables } \\
\hline Sex prior week & & $\begin{array}{c}0.06 \\
(0.17)\end{array}$ & & \\
\hline No sex, contraception & & & $\begin{array}{c}-1.90 \\
(0.24)\end{array}$ & \\
\hline No sex, no contraception & & & $\begin{array}{c}-0.99 \\
(0.34)\end{array}$ & \\
\hline Sex, consistent contraception & & & $\begin{array}{c}-1.94 \\
(0.26)\end{array}$ & \\
\hline Sex, inconsistent contraception & & & $\begin{array}{l}-1.25^{* * *} \\
(0.27)\end{array}$ & \\
\hline No sex, other hormonal & & & & $\begin{array}{l}-3.03^{* *} \\
(1.04)\end{array}$ \\
\hline No sex, pill & & & & $\begin{array}{l}-2.47^{* * *} \\
(0.56)\end{array}$ \\
\hline No sex, nothing & & & & $\begin{array}{l}-0.98^{* * *} \\
(0.23)\end{array}$ \\
\hline Sex, other hormonal & & & & $\begin{array}{l}-2.72 * * * \\
(0.56)\end{array}$ \\
\hline Sex, pill & & & & $\begin{array}{l}-1.97^{* * *} \\
(0.33)\end{array}$ \\
\hline Sex, coital & & & & $\begin{array}{l}-1.38^{* * *} \\
(0.24)\end{array}$ \\
\hline Log-likelihood & -1002.77 & -1002.71 & -969.74 & -963.87 \\
\hline Pseudo $R^{2}$ & 0.11 & 0.11 & 0.14 & 0.14 \\
\hline
\end{tabular}

${ }^{*} p<0.05 ; * * p<0.01 ; * * * p<0.001$.

variables in the context of the control variables was $35.8 \%$, with a relatively broad range of $18.5 \%$ to $60.1 \%$. As a result of the addition of the best performing mediator variables, the $t$-ratio score of five of the eleven predictor variables decreased and became non-significant. These variables (their percentage decrease) were: desires to become pregnant $(63.4 \%)$, antinatal non-polar dummy (37.4\%), perceived partners' desires to become pregnant $(34.7 \%)$, perceived partners' desires to avoid pregnancy $(21.1 \%)$ and perceived partners' ambivalent/indifferent dummy (60.1\%). 


\section{Discussion}

The theoretical approach of this paper rests on the premise that important contributors to unplanned pregnancy among unmarried young women are both the positive and negative desires they have for pregnancy and, especially, the interactions between them. If this premise is true, it should be possible to demonstrate in data analytic models not only that the women who get pregnant have certain motivational profiles that directly predict the occurrence of pregnancy but also that including their sexual and contraceptive behaviours in those models as mediators will reduce, and in some cases even eliminate, the strength of that direct prediction.

This study has tested four groups of predictor variables that represent different versions of positive and negative pregnancy desires, including in each case group a base model without sexual and contraceptive mediators and three models with mediators based on different sexual and/or contraceptive behaviours. The results shown in Tables 4 to 7 indicate that regardless of the type of predictors in the model - the women's own positive and negative desires, their perception of their partners' positive and negative desires, or either of the two types of dummy variables representing interactions between those positive and negative desires - there are substantial reductions in these predictors' coefficients once the mediators are introduced. These reductions can be quantified in two ways: first, four of the ten pregnancy desires predictor variables that were significant in the models without mediators became non-significant after the best performing mediators were added; and, second, the $t$-ratios of the remaining six desires predictor variables that were significant in the model without mediators decreased by an average of $29.6 \%$ after the best performing mediators were added (calculations not shown). Thus the results clearly support the conclusion that sexual and contraceptive behaviours mediate the effects of the women's pregnancy desires and their perception of their partners' desires on the risk of pregnancy.

Still, the fact that more than half of motivational predictors retained an appreciable amount of direct prediction of pregnancy risk even after the best mediators had been added to the models requires further consideration. There are a number of factors that may contribute to this finding. One such factor is measurement error. In light of the statistical significance of the No sex, No contraception moderator variable in all four tables, there appears to be some measurement error that is related to some women being incorrectly classified with respect to which week they were having sex. This, however, is only the measurement error that is recognized. It is highly likely that there is an additional unknown amount of error related to the measurement of key constructs used in this study. Further, it seems quite possible that these errors have contributed to the retained direct prediction of pregnancy risk by the motivational variables after the addition of the behavioural mediators.

A second contributory factor is unmeasured behaviour. Contraceptive behaviour can be quite complex and variable across time periods, especially among youth, who may not have the benefit of a consistent partner and/or consistent opportunities for sexual behaviour. Three levels of consistency of contraceptive use and three categories of contraceptive methods are unlikely to do full justice to these complexities and variabilities.

A third contributory factor is a cognitive one. There are many aspects of cognition that are known to play an important role in risk assessment, motivational regulation and 
the management of conflict relative to unplanned pregnancy (Miller, 2015). In one study, Miller (1975) gave 642 young women seeking an abortion a check-list of 53 psychological/behavioural items that might have played a role in their getting pregnant and asked them to check all that applied to them. The following are some of the items especially relevant to the current discussion and the percentage of their endorsement: I thought it was during the safe period $(35 \%)$; I put the possibility of pregnancy out of my mind (21\%); I decided to take a chance and count on good luck $(12 \%)$; My judgment was affected by alcohol or marijuana $(8 \%)$. These are just a few of the cognition-related factors that might be expected to influence whether or not sexual or contraceptive behaviours mediate the relationship between motivation and pregnancy risk. The one purely cognitive variable that was included in the mediational analyses perceived subfecundity - did not prove to be significant. However, this measure was constructed post hoc from available interview questions and had no previously established validity, apart from face validity.

Finally, a fourth factor is one related to partner effects. Although perceived partner motivational predictors have been included in the current research, no direct measures of partners' desires or, of equal importance, partners' reports of their own behaviours have been included. Because there are two individuals in play during heterosexual and contraceptive behaviours, there is an additional unobserved level of motivation and behaviour that can influence how mediators affect the direct prediction of pregnancy risk.

There are several noteworthy variations in effects across the reported models. One is the difference between the strength of the women's core desires (Table 4) and their perceptions of their partners' core desires (Table 6). For the women themselves, it is their desires to avoid pregnancy that are stronger than their desires to become pregnant, both before and after the introduction of mediators. In contrast, it is the women's perceptions of their partners' desires for pregnancy that are stronger. This finding is suggestive of a dynamic where the value of a pregnancy to an unmarried young woman is more negative than it is to an unmarried young man, at least as she perceives it.

Another noteworthy variation is the difference between the strength of the women's quadrant-based desires shown in Table 5 and the strength of the women's perceived partners' constrained desires shown in Table 7. Among the latter three, the perceived partners' constrained pronatal predictor displays the strongest coefficients of any model before or after the introduction of mediators. In addition, the other two perceived partners' constrained predictors are weaker initially than the first three of Table 5. Further, the ambivalent/indifferent predictor loses significance after the introduction of mediators. These patterns indicate that the constrained pronatal predictor, which includes women who are pronatal, ambivalent or indifferent and who perceive their partner as pronatal, predicts the highest risk of pregnancy of any variable tested in all of the models. This finding is suggestive of a dynamic where the value of a pregnancy to an unmarried young woman is not sufficiently negative to overcome the very positive value it appears to have for the man who is her partner. This dynamic and the one described in the previous paragraph highlight the potential usefulness of interacting women's perceptions of their partners' desires with the women's own desires.

The best performing base model occurs in Table 7. Its predictors are based on interactions between the women's and their perceived partners' quadrant-based dummy variables, indicating that both the women's desires and their perceptions of their 
partners' desires contribute to model performance. The best performing model with mediators present also occurs in Table 7. Its three mediators that are based on having sex and using contraception indicate that using one of three categories of contraceptive methods decreases pregnancy risk relative to using no method, approximately in proportion to the use effectiveness of the specific method categories. The three mediators that are based on not having sex and using one of two methods or using nothing are almost certainly confounded by the previously discussed measurement error. Thus the highest negative coefficient $(-3.03)$ reflects women who are the most protected group because they are all using the most effective contraception, with only a small subsample actually having sex. Similarly, the lowest negative coefficient $(-0.98)$ reflects women who are the most unprotected group because they are all using nothing, with a small subsample actually having sex.

Because of the ambiguity caused by the measurement error associated with the variable measuring sex/no sex during the prior week, it is not possible to draw any firm conclusions about the relative importance of sexual and contraceptive behaviours as mediators of pregnancy desires and unplanned pregnancies. However, considering the overall results of the four sets of mediation models, it is quite clear that both the consistency of contraceptive method use and the type of contraceptive method used have important mediational effects. A study by Santelli et al. (2007) found that $86 \%$ of the reduction in pregnancy risks among adolescent girls (ages 15-19) was due to contraceptive use and the remainder was due to declines in sexual activity. More recent studies by the same group (Santelli et al., 2009; Lindberg et al., 2016) have continued to confirm the general proportionality of those initial findings. The noted ambiguity of the current study's measurement of sexual behaviour notwithstanding, the mediational findings reported above are entirely consistent with the findings of Santelli, Lindberg and colleagues that during late adolescence contraceptive behaviours play a predominant role relative to sexual behaviours in the regulation of pregnancy risk.

It is noteworthy that those variables in the current study that retain the most direct prediction of pregnancy risk in the presence of the best performing mediators are not those based solely on the women's core desires or the perceived core desires of their partners (Tables 4 and 6). Rather they are based on the women's four quadrant-based desires (Table 5) and the three interaction variables based on the women's and their perceived partners' desires (Table 7). These findings should encourage the development of models that include both positive and negative desires, as well as interactions between those desires. They should also encourage the inclusion of the women's perceptions of their partners' desires, as well as interactions between their own and their perceived partners' desires. Finally, when pursuing models of the sort reported here with their considerable complexity, it may be helpful to keep in mind that the five factors discussed above may come into greater play as possible explanations for why mediation variables in such models do not eliminate all direct prediction of pregnancy risk by motivational and related variables.

\section{Acknowledgments}

This research was supported by three grants from the National Institute of Child Health and Human Development (R01 HD050329, R01 HD050329-S1, R03 HD077051, PI Barber), a grant from the National Institute on Drug Abuse (R21 DA024186, PI Axinn) 
and a population centre grant from the National Institute of Child Health and Human Development to the University of Michigan's Population Studies Center (R24 HD041028). The authors gratefully acknowledge the Survey Research Operations (SRO) unit at the Survey Research Center of the Institute for Social Research for their help with the data collection, particularly Vivienne Outlaw, Sharon Parker and Meg Stephenson. The authors also gratefully acknowledge the intellectual contributions of the other members of the original RDSL project team: William Axinn, Mick Couper, Steven Heeringa and Yasamin Kusunoki, as well as the Advisory Committee for the project: Larry Bumpass, Elizabeth Cooksey, Kathie Harris and Linda Waite. The authors have no Conflicts of Interest to declare.

\section{References}

Barber, J. S., Kusunoki, Y. \& Gatny, H. H. (2011) Design and implementation of an online weekly journal to study unintended pregnancies. Vienna Yearbook of Population Research $\mathbf{9}$, 327-334.

Cole, L. A. (2011) The utility of six over-the-counter (home) pregnancy tests. Clinical Chemistry and Laboratory Medicine 49, 1317-1322.

Lindberg, L. D., Santelli, J. S. \& Desai, S. (2016) Understanding the decline in adolescent fertility in the United States, 2007-2012. Journal of Adolescent Health 59, 577-583.

Miller, W. B. (1975) A survey of psychological antecedents of conception among abortion seekers. Western Journal of Medicine 122, 12-19.

Miller, W. B. (1994) Childbearing motivations, desires, and intentions: a theoretical framework. Genetic, Social, and General Psychological Monographs 120, 223-258.

Miller, W. B. (2015) The Childbearing Motivational System: Consciousness, Executive Functions, and the Neural Substrate. doi: 10.13140.RG.2.1.2643.0165.

Miller, W. B., Barber, J. S. \& Gatny, H. H. (2013) The effects of ambivalent fertility desires on pregnancy risk in young women in the U.S.A. Population Studies 67, 25-38.

Miller, W. B., Barber, J. S. \& Schulz, P. (2016) Do perceptions of their partners' childbearing desires affect young women's pregnancy risk? Further study of ambivalence. Population Studies 71(1), 101-116.

Miller, W. B. \& Pasta, D. J. (1995) Behavioral intentions: which ones predict fertility behavior in married couples? Journal of Applied Social Psychology 25, 530-555.

Miller, W. B. \& Pasta, D. J. (2000) Early family environment, reproductive strategy, and contraceptive behavior: testing a genetic hypothesis. In Rodgers, J. L., Rowe, D. C. \& Miller, W. B. (eds) Genetic Influences on Human Fertility and Sexuality: Theoretical and Empirical Contributions from the Biological and Behavioral Sciences. Kluwer, Boston, pp. 183-230.

Miller, W. B. \& Pasta, D. J. (2002) The motivational substrate of unintended and unwanted pregnancy. Journal of Applied Biobehavioral Research 7, 1-29.

Miller, W. B., Trent, M. \& Chung, S. (2014) Ambivalent childbearing motivations: predicting condom use by urban, African-American, female youth. Journal of Pediatric Adolescent Gynecology 27, 151-160.

Santelli, J. S., Lindberg, L. D., Finer, L. B. \& Singh, S. (2007) Explaining recent declines in adolescent pregnancy in the United States: the contribution of abstinence and improved contraceptive use. American Journal of Public Health 97, 150-156.

Santelli, J. S., Orr, M., Lindberg, L. D. \& Diaz, D. C. (2009) Changing behavioral risk for pregnancy among high school students in the United States, 1991-2007. Journal of Adolescent Health 45, 25-32. 